NBER WORKING PAPER SERIES

\title{
SUGGESTED SUBSIDIES ARE SUB-OPTIMAL UNLESS COMBINED WITH AN OUTPUT TAX
}

\author{
Don Fullerton \\ Robert D. Mohr \\ Working Paper 8723 \\ http://www.nber.org/papers/w8723
NATIONAL BUREAU OF ECONOMIC RESEARCH
1050 Massachusetts Avenue
Cambridge, MA 02138
January 2002

For funding this research, we thank the University of Texas and the National Science Foundation (grant \#SBR9811324). Helpful suggestions were provided by Robert Deacon, Art O'Sullivan (formerly Sullivan), John Stranlund, Sarah West, and Roberton Williams III. This paper is part of the NBER's research program in Public Economics. The views expressed herein are those of the authors and not necessarily those of the National Bureau of Economic Research or the National Science Foundation.

(C) 2002 by Don Fullerton and Robert D. Mohr. All rights reserved. Short sections of text, not to exceed two paragraphs, may be quoted without explicit permission provided that full credit, including $\odot$ notice, is given to the source. 
Suggested Subsidies are Sub-optimal Unless Combined with an Output Tax

Don Fullerton and Robert D. Mohr

NBER Working Paper No. 8723

January 2002

JEL No. H23, H25, Q24, Q28

\begin{abstract}
Because of difficulties measuring pollution, many prior papers suggest a subsidy to some observable method of reducing pollution. We take three papers from the Journal of Environmental Economics and Management as examples, and we extend them to make an additional important point. In each case, we show that welfare under the suggested subsidy can be increased by the addition of an output tax. While the suggested subsidy reduces damage per unit of output, it also decreases the firm's cost of production and the equilibrium break-even price. It might therefore increase output -- unless combined with an output tax. Using one example, we show that a properly-constructed subsidy-tax combination is equivalent to a Pigovian tax. Another example is a computational model, used to show that the subsidy-tax combination can yield a welfare gain that is more than three times the gain from using the subsidy alone. The third example is a theoretical model, used to show that the subsidy alone increases production and thus could increase total pollution. An additional output tax offsets this increase in production.
\end{abstract}

Don Fullerton

Department of Economics University of Texas at Austin

Austin, TX 78712

and NBER

dfullert@eco.utexas.edu
Robert D. Mohr

Department of Economics University of New Hampshire

Durham, NH 03824

rmohr@cisunix.unh.edu 
Many existing papers point out that a direct tax on a socially-damaging activity may be costly or impossible to monitor and enforce, and many proceed to suggest and analyze a policy that would instead just subsidize an alternative to the damaging activity. Three examples have appeared in the Journal of Environmental Economics and Management, and they provide very different models of different environmental problems. In the first of these examples, Deacon [2] develops a general equilibrium model of deforestation and points out that "the use of Pigovian taxes or marketable permits can be expected to encounter the same monitoring and enforcement problems that keep the market from providing forest services efficiently" (p. 17). He analyzes a subsidy to non-forest inputs. Second, Sullivan [9] develops a partial equilibrium model of toxic waste disposal and points out that "attempts to impose marginal-cost pricing on illegal disposers would generate substantial monitoring costs" (p.58). He analyzes a subsidy for legal disposal, which decreases illegal disposal but "also causes the underpricing of toxic disposal, generating efficiency cost in the form of an excessive volume of toxic waste" (p.59). Third, Stranlund [8] develops an enforcement model of air pollution and notes that "when monitoring is difficult because the sources of pollution are widely dispersed or because emissions are not measured easily as in nonpoint pollution problems, regulators should be motivated to consider substituting technological aid for direct enforcement" (p. 229). In other words, a subsidy for control technology can substitute for other policy tools in overall efforts to reduce pollution.

All of these papers provide correct and useful analyses of these subsidies. Deacon demonstrates the effects of the subsidy policy on deforestation; Sullivan computes the potential benefit offered by a subsidy to proper waste disposal; and Stranlund shows that a subsidy might serve as a substitute for costly monitoring. Each paper achieves its objective. Here, we simply extend those models to make an additional important point: welfare under each of those suggested subsidies can be further increased by the addition of an output tax. 
This general point has appeared in prior literature. Both Eskeland and Devarajan [4] and Walls and Palmer [15] discuss combinations of instruments that can substitute for a Pigovian tax. Fullerton [5] shows that the effects of a tax on a dirty input can be matched by the combination of a subsidy to clean inputs and a tax on output (a combination he calls a "two-part instrument"). Fullerton and Wolverton [7] provide closed-form solutions for the first-best two-part instrument. The general presumption in these papers is that a tax can readily be imposed upon any market transaction such as the sale of a final good or service, because the invoice can be verified by the other party to the transaction. Similarly, eligibility for a subsidy can be verified for clean market inputs such as the use of labor, capital, or legal disposal, or the purchase of forest-conserving technologies or abatement technologies. Problems arise with Pigovian taxes because the producer makes no market transaction for deforestation, dumping, or emissions. Trees can be cut without any record that they ever existed. Illegal waste can be dumped at midnight. Emissions are self-reported. Without expensive audits, they are relatively easy to hide.

The contribution of the current paper, then, is to demonstrate the usefulness of this twopart instrument by applying it to these three specific contexts. Because these examples are so diverse, we hope to demonstrate how the concept could be applied in many other contexts as well. To show that it is not limited to the cases considered by Fullerton and Wolverton, we demonstrate the two-part instrument within each of the three pre-existing models, using the same equations and notation as in each prior paper. In each case we analyze the same suggested subsidy policy, and we add a tax on output. In two cases, this step requires that we extend the prior model to consider the output market. In each of these three diverse examples, we show that this policy combination raises welfare.

The intuition can be simply stated. In each case, the unavailable Pigovian tax would raise the relative price of the damaging input and induce firms to substitute into the other input, reducing damage per unit of output (the "substitution effect"). It would also raise the price of 
output and thus reduce the number of units (the "output effect"). The suggested subsidy in each case would make a similar change to relative input prices and can thus reduce damage per unit of output, but it decreases the firm's cost of production and therefore decreases the equilibrium break-even price. Thus the subsidy alone might increase output and could increase total pollution. The two-part instrument uses the same subsidy to achieve the desired substitution effect, and it uses the output tax to fix the output effect.

The point is that many prior papers have unnecessarily limited the menu of policy options. They correctly point out that measurement of emissions (to implement a Pigovian tax or emissions standard) may be difficult or impossible, and that a subsidy to the clean alternative is feasible because it applies to a market transaction. However, an output tax is equally feasible because it also applies to a market transaction. The combination of the proposed subsidy with this equally-feasible output tax is shown here to attain a higher level of welfare.

The remainder of this paper consists of four sections: one for each of the prior models and one to conclude. We start with Deacon's [2] model of deforestation because we can use it to provide a simple introduction of our theory. The following section uses Sullivan's [9] computational model of toxic waste, and the third section uses Stranlund's [8] model of technological adoption.

\section{A Model of Deforestation}

Deacon [2] develops a general equilibrium model of deforestation and derives a Pigovian tax. He then considers the possibility that such a tax is unenforceable, and he studies the effects of several alternatives. We briefly outline the key features of Deacon's model, and we then show that if one of his alternatives, "employment opportunity enhancement" (Deacon, p.1), is combined with a general tax on output, then agents respond as if they faced a Pigovian tax. 
Deacon's model depicts a small open economy populated by identical individuals. The representative agent gets utility from three sources:

$$
W=W\left(x^{c}, y^{c}, Q\right)
$$

where $x^{c}$ denotes the consumption of a forest-using good, $y^{c}$ denotes the consumption of a numeraire that does not require any forest inputs to produce, and $Q$ is the service flow from undestroyed forest.

The amount of land is normalized to one unit per individual. Land can be left as forest or it can be used in production of $X$. The proportion used in production is denoted by $P$, so:

$$
Q+P=1
$$

The production functions for $X, Y$, and $P$ are:

$$
\begin{aligned}
& X=X\left(L^{X}, P\right) \\
& Y=\alpha L^{Y} \\
& P=(\alpha \beta) L^{P}
\end{aligned}
$$

where $X$ is produced using labor $\left(L^{X}\right)$ and cleared land $(P), Y$ is produced using only labor $\left(L^{Y}\right)$ times a constant $(\alpha)$, and the clearing of land $(P)$ uses labor $\left(L^{P}\right)$ times another constant $(\alpha / \beta){ }^{1}$ Each agent's endowment of labor is normalized to one:

$$
1=L^{P}+L^{X}+L^{Y}
$$

The economy trades internationally, and the value of exports must equal the value of imports:

\footnotetext{
${ }^{1}$ This formulation implies that $\alpha$ and $\beta$ are the effective prices of the two inputs in the production of $X$ (labor and cleared land, respectively).
} 


$$
v x^{e}=y^{m}
$$

where $x^{e}$ denotes exports of good $X, y^{m}$ denotes the imports of good $Y$, and $v$ is the relative world price of $X$. Good $Y$ is the numeraire. All production must be consumed or traded, so:

$$
\begin{aligned}
& y^{m} \equiv y^{c}-Y \\
& x^{e} \equiv X-x^{c}
\end{aligned}
$$

To represent the social planner's problem, Deacon inserts the information contained in the preceding eight equations (1.2) - (1.9) into the utility function (1.1) and maximizes. Rearranging the optimal first-order conditions yields:

$$
\begin{aligned}
& \frac{X_{L}}{X_{P}}=\frac{\alpha}{\left(W_{Q} / W_{y}\right)+\beta} \\
& \frac{W_{x}}{W_{y}}=v \\
& v X_{P}=\frac{W_{Q}}{W_{y}}+\beta
\end{aligned}
$$

where subscripts denote partial derivatives (e.g. $X_{L}=\partial X / \partial L^{X}$ and $W_{x}=\partial W / \partial x^{c}$ ). Equation (1.10a) shows that inputs into $X$ are selected so that the ratio of marginal products equals the ratio of their marginal social costs, where the latter includes the marginal value of forgone forest services $\left(W_{Q} / W_{y}\right)$. Equation (1.10b) shows that consumers match the ratio of marginal utilities to the ratio of prices $(v / 1)$. Finally, $(1.10 \mathrm{c})$ shows that deforestation optimally stops at the point where the value of the marginal product of deforestation equals the marginal social cost. Combined, these three conditions fully describe the efficient equilibrium. 
To see how this social planner's solution compares to a market equilibrium, Deacon lets each agent regard the flow of forest services $(Q)$ as fixed. Furthermore, he allows government three policy instruments. In his model, $\tau$ is a tax on exports $\left(x^{e}\right), \lambda$ is a tax on labor $\left(L^{X}\right)$, and $\pi$ is a Pigovian tax on deforestation $(P)$. He shows that the Pigovian tax achieves all the optimal conditions $(1.10 \mathrm{a}-1.10 \mathrm{c})$, but neither $\tau$ nor $\lambda$ can do the job. The export tax $\tau$ may reduce the production of $X$, but it provides no incentive to substitute away from $P$. A labor subsidy ( $\lambda$ $<0$ ) can induce substitution away from $P$, but might encourage production.

Thus, Deacon accomplishes his goal of showing economic effects of each instrument. He does not try to find second-best rates (which do not have closed-form solutions anyway), but he does show that an increase in $\lambda$ (from $\lambda=0$ ) might raise or lower welfare. Thus, we infer that the second-best employment tax $\lambda$ might be positive (to discourage production of the forestusing good $X$ ) or negative (to encourage substitution in production towards $L^{X}$ and away from $P)$. In this extension, we change the model in only one respect: instead of saying that $\tau$ applies only to exports, we let the tax apply to all production of $X$. With this single change, we provide closed-form solutions for $\lambda$ and $\tau$ that have unambiguous signs, a combination that induces agents to act as if they faced a Pigovian tax - even when $\pi$ is unavailable.

The first-order conditions for the market equilibrium are derived from the separate maximization problems of the consumer and the producer. ${ }^{2}$ We place all three possible tax rates into the producer's problem. Thus, every unit of $X$ generates revenue of $(v-\tau)$ for the producer, while every unit of $x^{c}$ costs the consumer $v$. The individual consumer (who regards $Q$ as fixed) chooses consumption goods to maximize $W\left(x^{c}, y^{c}, Q\right)$ subject to the budget constraint. Therefore: 


$$
\frac{W_{x}}{W_{y}}=v
$$

This market condition always matches the second social planner's condition (1.10b).

To maximize profits under a fixed set of world prices, producers allocate labor among its three possible uses. These producers also ignore the damage imposed by deforestation, but they do account for the cost of taxes $(\pi, \tau, \lambda)$. The production problem is to maximize:

$$
\mathscr{L}=(v-\tau) X\left(L^{X},(\alpha / \beta) L^{P}\right)+\alpha L^{Y}-\pi\left[(\alpha / \beta) L^{P}\right]-\lambda L^{X}+\mu\left[1-L^{X}-L^{Y}-L^{P}\right]
$$

with respect to the choices, $L^{X}, L^{Y}$, and $L^{P}$. The first-order conditions are:

$$
\begin{aligned}
& (v-\tau) X_{L}=\lambda+\mu \\
& (v-\tau)\left(\frac{\alpha}{\beta}\right) X_{P}=\pi\left(\frac{\alpha}{\beta}\right)+\mu \\
& \alpha=\mu
\end{aligned}
$$

Combining these conditions produces:

$$
\frac{X_{L}}{X_{P}}=\frac{(\alpha+\lambda)}{(\beta+\pi)}
$$

If all taxes were zero $(\lambda=\pi=\tau=0)$, then producers set $X_{L} / X_{P}=\alpha / \beta$, which violates (1.10a). Thus, the unregulated equilibrium is inefficient. As Deacon shows, if government adds a tax on deforestation at the rate $\pi=\mathrm{W}_{\mathrm{Q}} / \mathrm{W}_{\mathrm{y}}$ (keeping $\lambda=\tau=0$ ), then (1.14) matches (1.10a). Also,

\footnotetext{
${ }^{2}$ The approach used here differs slightly from the one employed by Deacon. He first derives the cost function for $X$ and then plugs that cost function into the consumer's budget constraint. The two approaches are equivalent.
} 
substitution of $(1.13 c)$ into (1.13b) shows that (1.13b) matches (1.10c). Thus, the use of a single Pigovian tax ensures that all three of the social planner's conditions are met.

As Deacon points out, a tax on deforestation might be difficult to implement and enforce. Farmers use their own labor and cut their own trees, so that neither $L^{P}$ nor $P$ are used in conjunction with a market transaction. Neither has an invoice that can be used to enforce a tax. If the sale of output is a market transaction, however, then $X$ is observed and the output tax $(\tau)$ may be more easily enforced.

If $\pi=0$, our point is that government can set:

$$
\begin{aligned}
& \lambda=\frac{-\alpha\left(W_{Q} / W_{y}\right)}{\beta+\left(W_{Q} / W_{y}\right)}<0 \\
& \tau=\frac{\left(W_{Q} / W_{y}\right)}{X_{P}}>0
\end{aligned}
$$

These provide closed-form solutions for first-best tax rates with unambiguous signs: the government must subsidize the non-forest input, $L^{X}$, and tax output $X$. The choice of $\lambda$ in (1.15) can be inserted into the firm's condition (1.14) to match the social planner's condition (1.10a). With this subsidy to labor by itself, however, the total amount of deforestation by producers would exceed the amount of the social planner in (1.10c). The tax on output in (1.16) ensures that this additional condition is met. By subsidizing labor and taxing output, we have shown that government can induce agents to act as if they faced a Pigovian tax.

A few caveats might be in order. First, in some cases, the output tax itself might be difficult to enforce. Subsistence farmers in developing nations may eat their own output or trade informally. Perhaps only exports can be taxed, as in Deacon's original paper. Still, however, the use of two instruments together must perform better than the use of each one alone. Second, if 
production uses several non-polluting inputs, then each must be subsidized. The solution may then involve more than the "two-part instrument" in equations (1.15) and (1.16). Third, heterogeneity matters. If parameters $\alpha$ or $\beta$ in production functions (1.4) and (1.5) differ among firms, then the optimal subsidy rate in (1.15) may differ. Perfect implementation could be complicated. Again, however, even a uniform subsidy and output tax must perform better than the uniform subsidy alone.

Therefore, this use of Deacon's model offers additional insight for policymaking. Because the single policy instrument $(\lambda)$ has ambiguous effects on deforestation, public policy is difficult to construct and evaluate. Here, in contrast, the combination of two instruments produces unambiguous effects. The subsidy to $L^{X}$ has the desired substitution effect away from $P$, but it reduces the cost of production. This would increase output, unless government offsets this effect with a separate output tax. The model now provides a clear directive to policymakers. Environmental policy can indeed subsidize the non-polluting input to production. That subsidy is only optimal, however, if combined with a tax on output.

\section{A Model of Toxic Waste Disposal}

Sullivan [9] builds a computational model and uses it to show how a subsidy to legal disposal can significantly reduce social costs associated with illegal dumping of toxic waste. However, this subsidy to legal disposal does have an important drawback. Even proper disposal of waste encumbers the environment and imposes costs on society, and this subsidy increases the amount of such waste. We show that the use of an output tax alleviates this problem. The output tax induces firms to produce less waste overall, and it generates revenue to help finance the subsidy program.

To show how a tax-subsidy combination could improve welfare within Sullivan's framework, we review his model, replicate his computational results, and then add an output tax. 
In order to model the effects of an output tax, we must modify Sullivan's framework. Most notably, we add consumers and their final output demand. We show that these modifications yield a factor demand curve and a measure of welfare that are perfectly consistent with Sullivan's assumptions. We replicate the welfare gain from Sullivan's subsidy to legal disposal, and we show that adding an output tax provides a welfare gain three times as large.

Sullivan's model consists of a set of nearly-identical firms that differ only with respect to how effectively they avoid detection when dumping waste illegally. Firms that can avoid detection most effectively choose to dispose of all their waste illegally, while other firms use legal disposal. The marginal firm is indifferent between legal and illegal disposal.

Each firm makes two decisions: how to dispose of waste (legally or illegally) and how much waste to produce. Each uses the disposal method that generates the smallest expected cost. The relative costs of illegal and legal disposal depend on the size of the subsidy to legal disposal, the government's resources devoted to detecting illegal disposal, and the heterogeneous trait of the firm. The firm decides how much waste to produce based on a downward-sloping factor demand curve for waste. The factor price is the firm's expected disposal cost. Thus, a subsidy changes all firms' relative factor prices and shifts some firms at the margin from illegal to legal disposal. But because the subsidy reduces the cost of disposal for all firms using legal disposal, it increases the chosen waste generated.

Sullivan's $m$ firms are ordered according to the likelihood of detection when dumping waste illegally. The first firm $(j=1)$ is the least likely to be observed, and the last firm $(j=m)$ is the most likely to be observed. Using Sullivan's notation, the probability of detection is a linear function $(\Phi+\tau j)$, where $\Phi$ and $\tau$ are constants (for any given level of enforcement). ${ }^{3}$

\footnotetext{
${ }^{3}$ Sullivan models $\Phi$ as a function of resources $(R)$ devoted to detection, and he calculates the effects on waste and welfare in his model from changes in the government's monitoring effort. Since we are concerned only with other policies (subsidies and taxes), we fix $R$ and thus $\Phi$.
} 
Thus, firm $j$ faces an expected cost or "price" per barrel of illegal dumping given by:

$$
P_{I}(j)=f \cdot(\Phi+\tau j)=765 \cdot(.014+.000018 j)
$$

where $f$ is the fine for illegal dumping, and where the right hand side shows Sullivan's parameter values. ${ }^{4}$ All firms face the same fixed private marginal cost of legal disposal $\left(C_{L}\right)$ and the same rate of subsidy $(s)$. Thus, all firms face a private price for legal disposal given by:

$$
P_{L}=C_{L} \cdot(1-s)=30 \cdot(1-s)
$$

Each firm chooses to dispose of waste in the least-cost manner, and so each faces a price of waste disposal given by $P_{w}(j)=\min \left[P_{L}, P_{I}(j)\right]$. To see how many firms dispose of waste illegally, note that the indifferent firm, $j^{\prime}$, faces the same cost for legal or illegal disposal. Set (2.1) equal to (2.2) and solve for $j$ :

$$
j^{\prime}=\frac{C_{L}(1-s)-\Phi f}{\tau f}
$$

The first $j^{\prime}$ firms dispose of waste illegally, while the remainder use legal disposal. Every firm $j$ has a downward-sloping demand for waste:

$$
w(j)=\frac{k}{P_{w}(j)}=\frac{30}{P_{w}(j)}
$$

where $k$ is a constant. ${ }^{5}$

\footnotetext{
${ }^{4}$ To choose parameter values, Sullivan uses direct evidence from disposal facilities in California and other prior empirical literature. For example, parameters in the firm's cost of illegal dumping are based on prior results from Ehrlich [3].

${ }^{5}$ When we extend the model to account for the output market, we will specify $k$ as a function of income and of parameters from a utility function and a production function.
} 
Before turning to measurement of the costs and benefits of a policy, it is worth noting that equations (2.3) and (2.4) will drive our results. Equation (2.3) shows that a subsidy has the desirable effect of inducing more firms to dispose of waste legally: higher $s$ means lower $j^{\prime}$. The subsidy also has the undesirable effect of decreasing the price of waste, $P_{w}(j)$, and therefore, increasing the quantity of waste demanded (in 2.4). We can offset the second effect, however, by adding a tax on output.

Sullivan models the social marginal cost of illegal disposal, $C_{I}$, to be constant. Using his notation and parameter values, the total social cost of illegal disposal is:

$$
T C_{I}=I \cdot C_{I}=I \cdot \psi \cdot C_{L}=I(8.5)(30)
$$

where $I$ is the volume of illegal waste, and $\psi$ is a constant greater than one (so that $C_{I}>C_{L}$ ). In contrast, the social marginal cost of legal disposal, $m c(L)$, increases linearly with legal waste, $L$, so $m c(L)=.003(L)$. Therefore, the total cost of legal waste is triangular:

$$
T C_{L}=.5 L \cdot m c(L)=.5 L(.003 L)
$$

The benefit to firm $j$ of generating waste $w(j)$ is the area below its factor demand curve (inverting equation 2.4$):^{6}$

$$
b(j)=\int_{0}^{w(j)} \frac{k}{\omega} d \omega
$$

The total benefit of waste is the sum across $m=10,000$ firms of all their individual benefits:

\footnotetext{
${ }^{6}$ Since the integral is not defined at the lower limit of integration, we follow Sullivan by using a lower limit of 0.001 in computations.
} 


$$
T B(W)=\int_{1}^{m} b(j) d j
$$

Taking the benefit of pollution (equation 2.8) and subtracting the costs (equations 2.5 and 2.6) yields the value of the waste market.

Net welfare is this value of waste minus the social cost of administering a policy. For Sullivan, this social cost includes a direct cost of enforcement $(R)$ and the excess burden of raising money for enforcement and for subsidies. Our own programs can replicate his results using his formulas, but in this paper, we omit his excess burden calculations for simplicity. ${ }^{7}$

We now modify Sullivan's model to allow for an output tax. We model consumer demand (and therefore output) in the simplest way that yields results consistent with Sullivan's model. We assume that each firm behaves competitively, earns zero profits, and receives a market price $\mathrm{P}_{\mathrm{x}}$ for its output $x$ (with index $j$ suppressed). ${ }^{8}$ For each output $x$, a representative price-taking consumer has a Cobb-Douglas demand function based on exogenous income, $y$, while facing ad valorem tax, $t$. Therefore:

$$
x=\frac{\mathscr{y}}{P_{x}(1+t)}
$$

where $\gamma$ is a preference parameter. We assume that $x$ is produced using toxic waste and some other input via Cobb-Douglas production, so the firm's expenditure on waste is a constant share of sales revenue:

\footnotetext{
${ }^{7}$ In addition, results in Bovenberg and de Mooij [1] raise doubts about the kind of excess burden calculation in Sullivan [9]. It is true that subsidies might have to be financed by raising some other distorting tax, like a wage tax, which would reduce the real net wage and reduce labor supply. However, the subsidy for waste disposal would reduce the equilibrium cost of goods sold and thus raise the real net wage. This effect partly offsets the change to excess burden.

${ }^{8}$ Since firms have different costs, we cannot assume that they all operate competitively in the same output market. Instead, therefore, we assume that the market is segmented so that each price-taking firm faces the demand of one representative price-taking consumer.
} 


$$
P_{w} w=\alpha P_{x} x
$$

To obtain the factor demand for waste, substitute (2.9) into (2.10) and solve for $w$ :

$$
w=\frac{\alpha \gamma /(1+t)}{P_{w}}=\frac{k /(1+t)}{P_{w}}
$$

This equation modifies (2.4) by the addition of an output tax. Since Sullivan used $k=30$, we

\begin{tabular}{|c|c|c|c|c|}
\hline & $\begin{array}{l}\text { Laissez- } \\
\text { faire }\end{array}$ & $\begin{array}{l}\text { Suggested } \\
\text { Subsidy }\end{array}$ & $\begin{array}{c}\text { Suggested } \\
\text { Subsidy with } \\
\text { Output Tax }\end{array}$ & $\begin{array}{c}\text { Optimal } \\
\text { Subsidy-Tax } \\
\text { Combination }\end{array}$ \\
\hline \multicolumn{5}{|l|}{ Policy variables } \\
\hline Subsidy rate & 0 & 0.349 & 0.349 & 0.643 \\
\hline Subsidy budget (thousand $\$$ ) & 0 & 150.5 & 71.7 & 193.0 \\
\hline Output tax rate & 0 & 0 & 1.10 & 1.80 \\
\hline Output tax revenue (thousand $\$$ ) & 0 & 0 & 523.8 & 642.9 \\
\hline \multicolumn{5}{|l|}{ Volume of disposal (barrels) } \\
\hline Legal & 8,600 & 14,378 & 6,847 & 10,004 \\
\hline Illegal & 2,241 & 1,307 & 623 & 0 \\
\hline Total & 10,841 & 15,685 & 7,470 & 10,004 \\
\hline Number of unlawful firms & 1,400 & 640 & 640 & 0 \\
\hline \multicolumn{5}{|l|}{ Benefits and costs } \\
\hline Benefit of waste (thousand $\$$ ) & 2,091 & 2,206 & 1,984 & 2,072 \\
\hline $\mathrm{TC}_{\mathrm{I}}$ (thousand $\$$ ) & 572 & 333 & 159 & 0 \\
\hline $\mathrm{TC}_{\mathrm{L}}$ (thousand $\$$ ) & 111 & 310 & 70 & 150 \\
\hline Net value of waste (thousand \$) & 1,408 & 1,563 & 1,755 & 1,922 \\
\hline Enforcement cost (thousands \$) & 20 & 20 & 20 & 20 \\
\hline Net welfare (thousand \$) & 1,388 & 1,543 & 1,735 & 1,902 \\
\hline Gain relative to laissez-faire & 0 & 155 & 347 & 514 \\
\hline
\end{tabular}
set $\alpha \gamma y=30$ to be consistent with Sullivan when the output tax is zero. ${ }^{9}$

Table I shows the results of our calculations. The first two columns show results when the output tax is zero, as in Sullivan [9]. The subsidy rate is zero in the first column, to replicate

\footnotetext{
${ }^{9}$ We have no need to specify separate values for $\alpha, \gamma$, and $y$. Each is an exogenous constant, and we need only their product.
} 
Sullivan's "Laissez-Faire" case, and it is .349 in the second column to replicate his "Optimum Subsidy" case. These results emphasize Sullivan's central point: when illegal disposal is hard to observe, a subsidy to legal disposal can be an effective policy tool. It reduces illegal waste by $42 \%$ (from 2,241 to 1,307 barrels), and it increases the welfare benefit of this market by $11 \%$ (from 1,388 to 1,543 in $\$$ thousands). The welfare gain is $\$ 155,000$. In doing so, however, this policy raises the total amount of waste by $45 \%$ (from 10,841 to 15,685 barrels).

The next two columns show that a tax-subsidy combination can improve upon the suggested subsidy policy. The third column calculates the benefit-maximizing output tax when the subsidy is still .349 , as in the previous column. If $t=1.10$, then the welfare gain relative to the laissez-faire equilibrium improves to $\$ 347$ thousand - more than twice the gain from the subsidy alone. The additional gain comes from reducing both legal and illegal waste.

The availability of an output tax means, however, that .349 is no longer the optimal subsidy rate. The fourth column of Table I shows the results of our search for the optimal values of both rates simultaneously. In this case, the optimal policy provides a subsidy of .643, large enough to induce all firms to dispose of waste legally, and it imposes a relatively large tax on output $(t=1.80)$. The net welfare benefit from this market is now $37 \%$ larger than with no policy, a gain of \$514 thousand - more than three times the gain from Sullivan's subsidy alone. The intuition behind this impressive gain is straightforward. In Sullivan's framework, the subsidy to legal disposal causes total waste to rise by $45 \%$. Even legal waste imposes a social cost. Therefore, this subsidy must be used in moderation. When the subsidy is combined with a sufficiently large output tax, however, the demands for both types of wastes fall. Government can then use the subsidy more aggressively to switch waste from illegal to legal disposal.

We next calculate what would be the optimal Pigovian tax, if it were available, and we find that the welfare-maximizing rate would be $\$ 19.29$ per barrel of illegal waste. The outcome of this calculation exactly matches the last column of Table I. Thus, in this model as well as the 
previous one, the optimal two-part instrument replicates the effects of the unavailable Pigovian tax - even though each part applies to an observable market transaction: a subsidy to legal disposal and a tax on sale of output.

Sullivan's computational model provides important insights into the problem of dumping toxic waste. Illegal dumping is hard to detect, so it's hard to tax. However, government can induce voluntary reductions of costly illegal waste by subsidizing legal disposal. The subsidy increases total waste, however, unless that subsidy is combined with an output tax.

\section{A Model of Technological Adoption}

Stranlund [8] analyzes three policy tools of a government that wants firms to abate pollution: an abatement standard $(s)$, the probability of an audit $(p)$, and publicly-provided technological assistance $(q)$ for pollution abatement technology. In order to achieve any abatement, government must use strictly positive amounts of the first two tools. If audits are expensive, Stranlund shows that a cost-minimizing government may also use positive amounts of technological assistance. By providing such assistance, the government can achieve a given level of abatement while doing fewer audits.

Stranlund's framework considers a risk-neutral firm that minimizes expected compliance cost while facing a standard stated in total emissions (or equivalently, total abatement). Here, we extend his model to analyze the trade-off between monitoring and technological aid when firms face a per-unit emissions or abatement standard. Thus we broaden the applicability of Stranlund's analysis, as per-unit standards are common policy tools. For example, policies to control mobile-source pollution focus on emissions per vehicle, rather than the hard-to-monitor total emissions. In addition, whereas Stranlund leaves implicit the firm's choice of output, we will add explicit consideration of how the per-unit abatement standard affects output choices. We can then add a tax on output. 
Whereas Stranlund allows output implicitly to change, and uses $a$ to represent total abatement, we use $a$ to represent abatement per unit. Similarly, the abatement standard $(s)$ represents the required abatement per unit of output. When all of Stranlund's variables are redefined to represent amounts per unit of output, we then simply note that all his derivations still hold and all his results can be re-interpreted to involve abatement or emissions per unit. We then add explicit changes in output and analyze what happens to total output and total emissions.

Extending the model in this way produces an interesting result. Because technological aid reduces costs to firms, equilibrium output rises. Therefore, while this aid increases abatement per unit, it also increases the number of units of output. Consequently, the effect of technological aid on total emissions is ambiguous. In many industries, the cost of pollution control equipment is negligible when compared to the industry's other costs. In these cases, the impact of a technology subsidy on output is likely to be negligible, and our extension does not significantly modify Stranlund's results. In other industries, however, pollution control is a significant fraction of overall costs. ${ }^{10}$ In these cases, we show that a cost-minimizing government may still wish to conduct environmental policy by using technological aid. However, the use of technological aid is sub-optimal unless accompanied by a tax on output.

As Stranlund models them, the compliance costs for reducing emissions consist of three parts. First, the firm pays the direct cost of abatement, $v(a, z)$, which depends on abatement and on the level of pollution control technology $(z)$. We re-define $a$ as abatement per unit and $v$ as the cost per unit, but all derivations follow Stranlund: the cost per unit rises with abatement $\left(\partial v / \partial a \equiv v_{a}>0\right)$ and falls with better technology $\left(\partial v / \partial z \equiv v_{z}<0\right)$. Second, the firm faces the

\footnotetext{
${ }^{10}$ U.S. Commerce Department [11] compares firms' expenditures on pollution abatement to the value of output. The data show significant variation by industry. For example, firms producing petroleum and coal products (SIC 29) spend about $2 \phi$ per dollar of output, while firms producing stone, clay and glass products (SIC 32) spend about one-tenth of that amount.
} 
cost of maintaining and using the technology, $w(z, q)$. This (per unit) cost increases as the level of technology increases $\left(w_{z}>0\right)$, but may be offset by a government subsidy or technological aid, $q$ (where $\left.w_{q}<0\right) .{ }^{11}$ Third, the firm may pay a fine if it does not fully comply with the "required" abatement standard $(s)$. The fine (per unit) is a function $f$ of the degree to which a firm "cheats", $(s-a)$, and the expected fine depends on the probability of an audit $(p)$. Overall compliance costs (per unit of output) are thus defined by:

$$
C(a, z)=v(a, z)+w(z, q)+p f(s-a)
$$

Here, we retain Stranlund's consideration of heterogeneity (even though we suppress his firmspecific index for notational simplicity). In principle, these costs can vary among firms both because firms have different ability to abate and because a regulator can set different abatement standards, probability of audit, degree of technological aid, and fine for non-compliance (even though Stranlund assumes that technological aid and fines are uniform).

To study Stranlund's policy options in a model where output varies, we add notation $x$ to denote output, and we say that the firm's "potential pollution" is proportional to output. In fact, we can define a unit of "potential pollution" as the amount associated with one unit of output. With no abatement per unit $(a=0)$, emissions are $x$. Then actual total emissions are:

$$
e=x(1-a)
$$

We also add a production function in terms of a single input, labor $(\ell)$, so that:

$$
x=g(\ell)
$$

\footnotetext{
${ }^{11}$ In Stranlund's formulation, government assistance comes in the form of a publicly-provided good that all firms may access. We do not consider the degree to which this aid is rival or excludable, so we use the terms "subsidy" and "technological aid" interchangeably.
} 
where $g_{\ell}>0$ and $g_{\ell \ell}<0$. Each price-taking firm faces the market price $P$ for its output, and it must pay an output tax $t$. Thus, the firm chooses $z, a$, and $\ell$ to maximize profits (II):

$$
\Pi(z, a, \ell)=g(\ell)[P-t-C(a, z)]-\ell
$$

where $\ell$ is the numeraire. After using equation (3.2) and simplifying, the problem produces the following first-order conditions:

$$
\begin{aligned}
& v_{z}(a, z)+w_{z}(z, q)=0 \\
& v_{a}(a, z)-p f^{\prime}(s-a) \leq 0 \quad[\text { if }<0, \text { then } a=s] \\
& g_{\ell} \cdot[P-t-C(a, z)]-1=0
\end{aligned}
$$

where the subscripts denote partial derivatives. The first two conditions are identical to those of Stranlund's model (his equations 2.2 and 2.3, p. 232). Thus, his comparative statics hold here as well: when firms do not fully comply $(a<s)$, they increase abatement in response to increased aid $\left(a_{q}>0\right)$, an increased standard $\left(a_{s}>0\right)$, or increased audits $\left(a_{p}>0\right)$. We merely reinterpret his results to show the effects of these policies on abatement per unit. Thus, we proceed directly to show effects on total pollution. Differentiating the first order conditions shows the output response to a technological subsidy:

$$
x_{q} \equiv g_{\ell} \cdot \ell_{q}=\frac{\left(g_{\ell}\right)^{2} \cdot w_{q}}{g_{\ell \ell} \cdot[P-t-C(a, z)]}>0
$$

The sign of this comparative static follows because $w_{q}$ and $g_{\ell \ell}$ are both negative while the net price $[P-t-C(a, z)]$ is positive. ${ }^{12}$ Therefore, equation (3.6) verifies that the subsidy $q$

\footnotetext{
${ }^{12}$ Because the firm has no fixed costs and decreasing returns to scale $\left(g_{\ell \ell}<0\right)$, any firm producing positive output must be making positive profits $[P-t-C(a, z)]$.
} 
reduces the firm's marginal cost and therefore raises its optimal level of output. Other comparative statics may be similarly derived. In particular, $x_{p}, x_{s}$, and $x_{t}$ are all negative. In addition, $a_{t}$ and $z_{t}$ are both zero: if a firm is already minimizing its cost per unit, then a tax on output does not affect abatement per unit or technology per unit. Since $e=x(1-a)$, these comparative statics define how each instrument affects total emissions:

$$
\begin{aligned}
& e_{p}=x_{p}(1-a)-x a_{p}<0 \\
& e_{s}=x_{s}(1-a)-x a_{s}<0 \\
& e_{t}=x_{t}(1-a)<0 \\
& e_{q}=x_{q}(1-a)-x a_{q} \gtrless 0
\end{aligned}
$$

where subscripts again denote partial derivatives. Stranlund shows that $a_{q}>0, a_{s}>0$, and $a_{p}>0$. Thus, we show here that total emissions $(e)$ are reduced by increased audits $(p)$, an increased standard $(s)$, or by an output tax $(t)$.

Equation (3.7d) looks at the effects of technological aid on emissions. Since both $a_{q}$ and $x_{q}$ are positive, the sign of $e_{q}$ depends on relative magnitudes. If abatement costs are only a small fraction of the firm's total costs, then $x_{q}$ may be quite small. If $x_{q}$ were zero, then the firm does not change output, and our extension reduces to Stranlund's original model. On the other hand, a technological subsidy might well affect output of the firm. From equation (3.7d), the condition for $e_{q}$ to be positive is $\frac{x_{q}}{x}>\frac{a_{q}}{(1-a)}$. Since $(1-a)$ is emissions and $-a_{q}$ is the change in emissions (both per unit of output), the firm's total emissions rise if the percentage change in output exceeds the percentage change in per-unit emissions. This condition may hold for any number of (heterogeneous) firms within an industry, and so it may hold for the aggregate as well. If so, then the subsidy to abatement may increase aggregate pollution. 
The possibility that technological aid may increase emissions (when the standard is per unit) is a fundamental change in Stranlund's result (where the standard was for total abatement). For example, Stranlund shows that if his total abatement standard is fixed and a regulator wants firms to cut total emissions, then the regulator can view monitoring and technological aid as substitutes. Using the same methodology as Stranlund, we next show that if the abatement standard is fixed per unit and the regulator still wants firms to cut total emissions, then monitoring and technological aid may no longer be substitutes. All else equal, increased aid may require more monitoring.

As in Stranlund, at this point, the abatement standard $(s)$ and the fine $(f)$ are fixed. The regulator optimally trades off the probability of an audit $(p)$ and the subsidy $(q)$ to induce the cost-minimizing choice of technology and abatement per unit. Since we add consideration of an output tax, our regulator must find the cost-minimizing combination $(q, t$, and $p)$ to achieve the target for total pollution $(e \leq \bar{e})$.

In order to derive the relationship between aid $(q)$ and monitoring $(p)$, let $p^{*}(q, t, \bar{e})$ be the minimum monitoring effort needed to achieve the compliance goal, $\bar{e}$, given any level of aid and tax. Stranlund uses first-order conditions (3.5a and 3.5b) to define the firm's choice of $a$ as a function of policy variables, $a(q, s, p)$. Since $s$ is fixed, this can be written as $a(q, p)$. Similarly, we use (3.5c) to define output $x$ as a function of all policy variables, $x(q, t, p)$. Therefore, the function $p^{*}$ is defined implicitly by:

$$
\bar{e}=x\left(q, t, p^{*}(q, t, \bar{e})\right) \cdot\left[1-a\left(q, p^{*}(q, t, \bar{e})\right)\right]
$$

Differentiate (3.8) with respect to $q$, rearrange, and use equations (3.7a) and (3.7d) to get:

$$
p_{q}^{*}=\frac{-e_{q}}{e_{p}} \gtrless 0
$$


This expression is analogous to equation (2.10) in Stranlund's model (p. 233). Because he is concerned with abatement in response to a total emission standard, he gets $p_{q}{ }^{*}=-a_{q} / a_{p}<0$. When firms face a per-unit standard, however, we just showed that the sign of $p_{q}{ }^{*}=-e_{q} / e_{p}$ is ambiguous (because the sign of $e_{q}$ is ambiguous). Regulators view monitoring and technological aid as substitutes only if increased aid leads to lowered pollution $\left(e_{q}<0\right)$.

Stranlund shows that technological aid can substitute for expensive audits when firms face a standard on total pollution. We have shown that this substitution may not hold if firms face a standard defined on pollution per unit of output. Nonetheless, we next show that if regulators have three tools $(q, p$, and $t)$, they can again view the first two as substitutes. That is, regulators may well substitute technological aid for monitoring, in this more general setting, if they can combine the technology subsidy with a tax on output. The intuition behind this conclusion is simple. A regulator can reduce pollution through various combinations of reduced output and increased abatement per unit, and the overall pollution goal can be accomplished in a two-stage process. The first stage we assume to be exactly the same as in Stranlund's paper (redefining variables per unit): the regulator chooses the levels of aid and monitoring to achieve the desired abatement per unit. With respect to this abatement, as Stranlund shows, monitoring and aid $d o$ act as substitutes. Thus, the regulator may want to use positive amounts of aid. Our extension focuses on the second part of the regulator's problem. Having achieved the desired abatement per unit, the regulator sets an output goal. Taking into account the optimal choices of monitoring and aid, the regulator sets the output tax to meet this second goal. Since abatement is not a function of the output tax, this choice does not alter abatement.

To model this two-stage problem, we adhere to Stranlund's model and allow the regulator to minimize the total social costs associated with regulation. In our extension, these costs can be 
split into two categories: the costs associated with a certain level of abatement per unit, plus the loss of consumer surplus associated with diminished output.

Stranlund identifies the costs associated with per-unit abatement as the sum of costs borne by the firm, $v(a, z)+w(z, q)$, and costs borne by government. The latter include the cost per audit, $r$, and the cost of aid (where the unit price of aid is normalized to one). Note that the expected fine, $p f(s-a)$, is a transfer, so it does not enter social costs. Maintaining the assumption that the standard is fixed, the expected social cost associated with the firm's abatement is $[v(a, z)$ $+w(z, q)+r p+q]$. Like Stranlund, we assume that this function is convex and that the regulator chooses $p$ and $q$ to minimize this cost of achieving a particular goal for $a .^{13}$ Given those choices $\left(p^{*}\right.$ and $\left.q^{*}\right)$, and the firm's optimal responses (including $z^{*}$ ), this cost can be defined as a function of the goal for $a$ :

$$
\Phi(a)=v\left(a, z^{*}\right)+w\left(z^{*}, q^{*}\right)+r p^{*}+q^{*}
$$

In addition, these policies reduce output and thus diminish consumer surplus. Let $\bar{x}$ represent the firm's output when government applies none of its policy tools. We then define $\Omega(\bar{x}-x)$ as the lost consumer surplus when decreasing output from $\bar{x}$ to $x$. To minimize the overall costs of achieving any particular reduction of pollution, the regulator therefore chooses $x$ and $a$ to minimize:

$$
\mathscr{L}=\Phi(a)+\Omega(\bar{x}-x)+\lambda(\bar{e}-x(1-a))
$$

This problem's first-order conditions describe the optimal mix of per-unit abatement $(a)$ and output reduction $(\bar{x}-x)$. The regulator chooses $p$ and $q$ (in 3.10) to achieve the optimal $a$.

\footnotetext{
${ }^{13}$ The goal for $a$ may be less than the standard, $s$, because firms may cheat when minimizing their own expected costs in equation (3.1).
} 
Then, output is controlled by choosing $t$ conditional upon those choices $\left(p^{*}\right.$ and $\left.q^{*}\right)$. In other words, if the regulator chooses to limit per-firm output to some level, $x^{*}$, then the optimal $t$ satisfies $x^{*}=x\left(p^{*}, q^{*}, t\right)$. Inverting this expression, we have the optimal tax rate: ${ }^{14}$

$$
t^{*}=t\left(p^{*}, q^{*}, x^{*}\right)
$$

Stranlund finds that a regulator can view monitoring and aid as substitutes, but we find this result does not hold with a per-unit emission standard. Nonetheless, Stranlund's basic intuition comes through unscathed. Our extension allows the regulator to solve the problem sequentially. Stranlund's model describes the first part of that sequence - how the regulator uses technological aid to minimize the costs of abatement per unit. Our contribution shows that different monitoring-subsidy combinations have different effects on output, which in turn affects pollution. However, the regulator can control output by using an output tax. Thus, Stranlund's results still hold, even if aid tends to increase pollution, but only if the regulator combines the optimal monitoring-aid package with an optimal output tax.

\section{Conclusion}

Deacon, Sullivan and Stranlund study an important and topical subject. Currently, regulators use a variety of environmental subsidies as policy tools. Just in the United States, we find several examples. The Department of Agriculture (USDA) sponsors a Cooperative Forestry Program that provides "technical and financial assistance to help rural and urban citizens, including private landowners, care for forests" [10]. Municipal trash and recycling collection programs subsidize the proper disposal of waste. Also, the Environmental Protection Agency

\footnotetext{
${ }^{14}$ Each parameter may differ among firms, and so the optimal value of this tax rate would differ among firms. Clearly, such a policy would be difficult to implement. Even a uniform output tax can improve upon the welfare gain from using only the abatement subsidy, however, and a computational version of this model could be used to show how much the gain exceeds that from a subsidy alone (or falls short of that from firm-specific taxes).
} 
(EPA) subsidizes new environmental technologies. The EPA's 33/50 Program disseminates information and offers technological assistance to firms in order to reduce air pollution (US EPA [13]), and the agency's Green Lights Program subsidizes energy efficient lighting (US EPA [14]). The Department of Energy (DOE) promotes the use of alternative energy sources, and it conducts basic research on how to abate and reduce pollution (US DOE [12]).

In combination, the papers of Deacon, Sullivan and Stranlund show that such subsidies have positive effects. Subsidies are especially appealing when a Pigovian tax is not available. With Deacon's model, we show that proper implementation of such a subsidy matched with an output tax is equivalent to a Pigovian tax. In Sullivan's computational model, a subsidy by itself increases social benefits by $11 \%$ (compared to the laissez-faire equilibrium). A subsidy-tax combination increases that gain to $37 \%$ of laissez-faire market benefits - more than three times the gain from using the subsidy alone.

Because Sullivan selected parameters to represent the toxic waste market, we have no reason to believe that these numerical results would generalize to other situations. The point is just to show a numerical example of our theoretical result. Another example is in Fullerton and West [6], where vehicle pollution is reduced by a subsidy to clean-car purchases, but the addition of a gas tax provides a welfare gain that is 3.5 times as large.

Our final example provides insight into this improvement. Using Stranlund's model with a per-unit standard, we show that a subsidy increases output. Therefore a subsidy, used alone, has ambiguous effects on pollution and may require increased monitoring. To prevent output from rising, however, regulators can use an output tax. Thus, indeed, a subsidy can help achieve optimal results. To do so, however, the regulator must combine it with a tax on output. 


\section{References:}

1. A. L. Bovenberg and R. A. de Mooij, Environmental levies and distortionary taxation, American Economic Review 84, 1085-1089 (1994).

2. R. Deacon, Assessing the relationship between government policy and deforestation, Journal of Environmental Economics and Management, 28, 1-18 (1995).

3. I. Ehrlich, Participation in illegitimate activities: An economic analysis, in "Essays in Economics of Crime and Punishment," (G. S. Becker and W. M. Landers, Eds.), National Bureau of Economic Research, New York (1974).

4. G. Eskeland and S. Devarajan, "Taxing Bads by Taxing Goods: Pollution Control with Presumptive Charges," World Bank, Washington DC (1996).

5. D. Fullerton, Environmental levies and distortionary taxation: comment, American Economic Review 87, 245-251 (1997).

6. D. Fullerton and S. West, Tax and Subsidy Combinations for the Control of Car Pollution, NBER Working Paper No. W7774 (July 2000).

7. D. Fullerton and A. Wolverton, The case for a two-part instrument, in "Environmental and Public Economics: Essays in Honor of Wallace E. Oates" (A. Panagariya, P. R. Portney and R. M. Schwab, Eds.) Edward Elgar, Cheltenham (1999).

8. J. Stranlund, Public technological aid to support compliance to environmental standards, Journal of Environmental Economics and Management 34, 228-239 (1997).

9. A. M. Sullivan, Policy options for toxic disposal: Laissez-faire, subsidization, and enforcement, Journal of Environmental Economics and Management 14, 58-71 (1987).

10. U.S. Department of Agriculture, "USDA Forest Service, State \& Private Forestry, Cooperative Forestry," web page, http://www.fs.fed.us/spf/coop/, USDA, Washington DC (July 13, 2000 version).

11. U.S. Department of Commerce (Bureau of the Census), "Pollution Abatement Costs and Expenditures: 1994" Current Industrial Reports; MA299(94)-1, U.S. Government Printing Office (1994).

12. U.S. Department of Energy, "Strategic Plan of the Office of Science," U.S. DOE, Washington DC (1999).

13. U.S. Environmental Protection Agency, "EPA's 33/50 Program Second Progress Report: Reducing Risk through Voluntary Action," U.S. EPA, Washington DC (1992).

14. U.S. Environmental Protection Agency, "Green Lights: An Enlightened Approach to Energy Efficiency and Pollution,” U.S. EPA, Washington DC (1993).

15. M. Walls and K. Palmer, Upstream pollution, downstream waste disposal, and the design of comprehensive environmental policies, Journal of Environmental Economics and Management 41, 94-108 (2001). 